\title{
Metrifonate was effective in mild to moderate Alzheimer's disease
}

\author{
Morris JC, Cyrus PA, Orazem J, et al. Metrifonate benefits cognitive, behavioral, and global function in patients with Alzheimer's \\ disease. Neurology 1998 May;50:1222-30.
}

\section{Question}

In patients with mild to moderate Alzheimer's disease (AD), is metrifonate safe and effective?

\section{Design}

26 week randomised, double blind, placebo controlled trial.

\section{Setting}

24 ambulatory clinics in the US.

\section{Patients}

408 patients (mean age 74 y, $61 \%$ women) who had probable AD according to the criteria of the National Institute of Neurological and Communicative Diseases and Stroke and the Alzheimer's Disease and Related Disorders Association, a Mini-Mental State Examination score of 10-26, a modified Ischemia Scale score $<4$, body weight of 45-94 kg (98-207 lbs), and contact with a caregiver $\geqslant 4$ times/week. Exclusion criteria included dementia from a cause other than probable $\mathrm{AD}$; cognitive impairment from toxic, alcoholic, or traumatic causes; clinically important medical problems; and previous treatment with metrifonate.

\section{Intervention}

After a loading dose of metrifonate, $100-180 \mathrm{mg}(2.0 \mathrm{mg} / \mathrm{kg}$ of body weight), for 2 weeks, 273 patients received $30-60 \mathrm{mg}$ of metrifonate $(0.65 \mathrm{mg} / \mathrm{kg}$ of body weight) for 24 weeks. 135 patients received a matching placebo.

\section{Main outcome measures}

Main outcome measures were cognitive function (Alzheimer Disease Assessment Scale-cognitive subscale [ADAS-Cog]) and global function (Clinician's Interview-Based Impression of Change with Caregiver Input scale [CIBIC-plus]). Secondary measures of function included the Neuropsychiatric Inventory (NPI). Measures of safety included dropout and adverse event rates.

\section{Main results}

The main analysis was by intention to treat. At 26 weeks of treatment, patients allocated to metrifonate showed a small improvement in cognitive function over baseline compared with a modest decline in congnitive function in the placebo group (ADAS-cog score mean change $-0.36 v+2.5$ points, $\mathrm{p}>0.001$ ). The overall difference in mean change in ADAS-cog scores was 2.86 (95\% CI 1.37 to 4.34$)$ in favour of the treatment group. Treated patients also declined less in global functioning than those in the control group. The mean CIBIC-plus score at 26 weeks was 0.28 (CI 0.06 to $0.50, \mathrm{p}=0.007$ ) points less in the treatment group. Metrifonate led to less incease in severity of impairment in the overall NPI score $(1.15 v 3.90, \mathrm{p}=0.0161)$ and on 6 of 10 items on the scale (hallucinations, agitation, depression, anxiety, apathy, and aberrant motor behaviour) although among these items the favourable effects was statistically significant only for hallucinations $(\mathrm{p}=0.002)$. More patients allocated to metrifonate than to placebo withdrew from treatment $\{\mathrm{p}=0.02\}^{*}$ and had adverse events that required discontinuation of treatment $\{p=0.002\} *$ (table). Severe adverse events did not differ between groups.

\section{Conclusions}

In patients with mild to moderate Alzheimer's disease, metrifonate led to a modest reduction in the rate of decline in cognitive and global function. Metrifonate was generally safe, but $12 \%$ of treated patients withdrew because of adverse events.

*p values calculated from data in article.

Metrifonate v placebo at 26 weeks in patients with Alzheimer's disease†

\begin{tabular}{lllll}
\hline Outcomes & Metrifonate & Placebo & RRI (95\% CI) & NNH (CI) \\
\hline Dropouts & $21 \%$ & $12 \%$ & $79 \%(9$ to 200$)$ & $11(7$ to 65$)$ \\
Dropouts from & $12 \%$ & $4 \%$ & $180 \%$ & $13(8$ to 46$)$ \\
$\quad$ adverse events & & & $(25$ to 541$)$ & \\
\hline
\end{tabular}

†Abbreviations defined in glossary; RRI, NNH, and CI calculated from data in article.

\section{Source of funding: Bayer}

For correspondence:DrJ C Morris, Department of Neurology, Washington University School of Medicine, Campus Box 8111, 660 South Euclid Avenue, St Louis, MO 63110-1093, USA. Fax +1314 4545279 .

\section{Commentary}

A theoretical advantage of metrifonate over other acetylcholinesterase (AchE) inhibitors is its metabolism to a form that binds irreversibly to the active site of the AchE enzyme. This well designed, executed, and analysed study by Morris et al adds to the growing body of evidence showing a modest, short term benefit of AchE inhibitors in patients with mild to moderate, uncomplicated AD. Relatively low dropout rates and alternative analyses provide convincing evidence of unbiased results. The consistency of a finding of modest improvement in almost all cognitive, behavioural, and psychiatric domains measured also supports the validity of the results, as does the finding of a dose response effect and a nearly identical main outcome in a previous dose finding study. ${ }^{1}$ Unfortunately, the magnitudes of the main effects of metrifonate are not substantially different from those found for tacrine, donepezil, and rivastigmine. The relatively low rate of side effects requiring study discontinuation testifies to a high degree of safety and tolerance, but is probably no better than for donepezil. A still unresolved question in $\mathrm{AD}$ treatment is whether the modest measurable, short term improvements from AchE inhibitors translate into any meaningful gain in quality of life. To the clinician completing the CIBC-plus, patients treated with metrifonate appeared essentially unchanged over 26 weeks, whereas those taking placebo on average appeared about midway between "un- changed" and "somewhat worse" by 26 weeks. The difference in ADAS-cog scores in this study suggests an average delay of about 5 months in expected cognitive decline (estimated at 3.5 to 5 points over 6 months). ${ }^{2}$ Of course, it is likely that some patients improved more than the mean and some less. A trial of an AchE inhibitor may be warranted in most patients with $\mathrm{AD}$, but this study does not add much to our understanding of how worthwhile this may be.

Roger Luckmann, MD, MPH

University of Massachusetts Medical Center Worcester, Massachusetts, USA

1 Cummings JL, Cyrus PA, Bieber F, et al. Neurology 1998:50:1214-21.

2 Farlow MR, Evans RM. Neurology 1998;51:S3644. 